\title{
Adolescência e morte: representações e significados
}

\author{
Elaine Teresinha Dal Mas Dias
}

\begin{abstract}
Resumo
Esta pesquisa analisa a representação da morte por sete adolescentes, alunos de uma escola privada do município de São Paulo. Acompanha longitudinalmente as mudanças ocorridas nesse processo, por intermédio de produções escritas realizadas nas aulas de Língua Portuguesa. A amostra é composta de 21 redações realizadas em anos alternados, iniciadas na $6^{a}$ série do ensino básico, mediadas pela leitura e discussão do livro $A$ morte tem sete herdeiros, e concluídas no $2^{\circ}$ ano do Ensino Médio. As composições mostram: discreta influência do texto literário, insignificante alteração decorrente do amadurecimento, a força da transmissão sociocultural de ideias e fantasias, a manutenção do conflito humano entre o natural e o inevitável, a permanência do sentido individual e singular das ressignificações das experiências coletivas e a negação do aniquilamento, mantida pela crença da reencarnação. Observa-se, ainda, a importância de um espaço escolar de reflexão sobre a morte.
\end{abstract}

Palavras-chave: Morte, adolescência, escola.

\section{Adolescence and death: representation and meaning}

\begin{abstract}
In this work we study the representation of death in seven adolescents. We follow longitudinally the possible changes resulting of such process. The corpus corresponds to 21 compositions carried out in alternate years, by seven students of a private school in S. Paulo city, starting in the $6^{\text {th }}$. Grade of elementary school, with the reading and discussion of Death has seven heirs, and ending in the second grade of high-school. The analyses of the productions show: little influence by the literary text and the strength of the socio-cultural transmission of ideas and fantasies on death. The results also reveal that the human conflict present in the binomial natural/inevitable does not eliminate the individual and singular sense of the re-attribution of signification to collective experiences and that the denial of annihilation by means of life after death is maintained by the belief in reincarnation. The importance of school space for reflection on death is considered important.
\end{abstract}

Key words: Death and dying, adolescence, school.

\section{Adolescencia y muerte: representaciones y significados}

\section{Resumen}

Esta investigación analiza la representación de la muerte por siete adolescentes, alumnos de una escuela privada del municipio de São Paulo. Acompaña, longitudinalmente, los cambios ocurridos en este processo, por intermedio de producciones escritas realizadas en las clases de Lengua Portuguesa. La muestra se compone de 21 redacciones realizadas en años alternados e iniciadas en el 60 año de la enseñanza básica, mediadas por la leitura y discusión del libro La muerte tiene siete herederos, y concluidas en el $2^{\circ}$ año de la Enseñanza Media. Las composiciones muestran: discreta influencia del texto literario, insignificante alteración a consecuencia de la maduración, la fuerza de la transmisión sociocultural de ideas y fantasías, la constancia del conflicto humano entre lo natural y lo inevitable, la permanencia del sentido individual y singular de las re-significaciones de las experiencias colectivas y la negación del aniquilamiento, mantenida por la creencia en la reencarnación. Se observa aún, la importancia de un espacio escolar de reflexión sobre la muerte.

Palabras Clave: Muerte, adolescencia, escuela. 


\section{Adolescência e morte:}

\section{representações e significados}

A linguagem, compreendida como base e instrumento do acervo coletivo, contempla ideias, mitos, noções e concepções, tipifica experiências, presentifica algo ausente espacial, temporal ou socialmente, transcende a realidade e expõe seu caráter intersubjetivo, na correspondência ininterrupta de sentidos e significados (Berger e Luckmann, 1966/1974). O conjunto de conhecimentos compartilhados é apreendido como verdade e, ao ser interiorizado, configura o indivíduo, constitui subjetividades e favorece a ressignificação de vivências coletivas.

Os fenômenos da morte e da adolescência fazem parte do imaginário sociocultural e são apropriados e representados conforme o contexto, o grupo e a época.

Na história da civilização ocidental, a morte é o "sujeito ausente do discurso" (Torres, 1983, p. 1) e o elemento "ausente do campo da consciência" (Morin, 1951/1970, p. 60 ), afastada do processo do viver como garantia da dilatação do tempo em vida. $E$ a adolescência é uma identidade miticamente posta e determinada como crítica e problemática, sobre a qual pairam desconfianças e temores.

Esta pesquisa tem por objetivo apresentar as representações de morte de um grupo de alunos do ensino básico e acompanhar as possíveis alterações durante o processo de amadurecimento. Pretende-se conhecer o modo como adolescentes de um determinado segmento social abordam, compreendem e expressam a perda concreta e definitiva determinada pela morte e a importância da participação da escola como espaço de reflexão e acolhimento. As indagações que se colocam são: como o adolescente representa a morte? A adolescência interfere na representação? A escola pode ajudar em momentos de luto? Como o professor trabalha esse fenômeno? O desvelamento do fenômeno e a aproximação do tema permanecem envoltos em mistério? A defrontação da realidade e os espaços de reflexão alteram essa percepção?

Entende-se representação como uma tradução construtiva do real, uma imagem global, subjetivamente apropriada e sempre percebida como presença objetiva; é um "ato constitutivo idêntico e radical do real e do imaginário" (Morin, 1980/2005a, p. 123, grifos do autor). Os fenômenos, fatos ou aspectos da vida, quando interiorizados, apresentam características particulares ao mesmo tempo em que se assemelham às concepções coletivas. Fantasia e realidade complementam-se em seus antagonismos e em elementos comuns que se interpenetram e interferem mutuamente. Desse conjunto dialógico surge a integração entre "a experiência pessoal e a coletiva/histórica armazenada na cultura e redistribuída em cada espírito via educação" (idem, p. 125).

Nessa perspectiva, o processo de representação recorre aos três princípios fundamentais do pensamento complexo moriniano: o recursivo, "no qual efeitos e produtos são necessários à sua produção e à sua própria causação" (Morin, Almeida, \& Carvalho, 2002, p. 64); o dialógico, por "afrontar realidades profundas que, justamente, unem verdades aparentemente contraditórias" (p. 64); e o hologramático, no qual "não apenas a parte está no todo mas o todo está na parte" (p. 65).

Pensar a morte reporta ao limite não aceito. Tratar o assunto com adolescentes e conhecer suas representações podem confirmar estudos realizados, revelar novas compreensões e oferecer perspectivas de intervenção.

\section{Introdução}

A morte tem sido um dos maiores desafios do homem. Presente na vida, é escamoteada pela ciência na busca incessante de sobrevida, pelo mito, na intenção de proteção e de imortalidade, e pela religião na garantia de um renascer, visando controle e superação. Como figura indizível da linguagem, apresenta-se na constante contradição entre o viver e o morrer e, como fenômeno absoluto, não pode ser anulado como evento físico. Carrega certezas e incertezas, ambiguidades e precisões envoltas na penumbra do desconhecido.

Ao se debruçar sobre os aspectos que envolvem a relação entre o homem e a morte, Morin (1951/1970) inicia seus estudos por intermédio das sepulturas encontradas nas comunidades rudimentares, em especial as neandertalenses e da pré-história do homem. Segundo sua ótica, a estreita ligação entre os homens vivos e os mortos é marcada pela presença de objetos, instrumentos e alimentos nos sepulcros e covas, que afirmam a individualidade do morto e sugerem reações de ordem emocional, como a negação da perda e a indicação do alongamento da vida. O autor considera fundamental a compreensão do utensílio e da "morte na sua presença contraditória e simultânea no seio da realidade humana primitiva" (Morin, 1951/1970, p. 24), observando que, nesses grupos, havia ritualizações e cuidados com o morto, que não era abandonado.

A relação do homem com a morte supõe, como propõe Morin (2001/2005b, p.46), "ao mesmo tempo, a consciência racional, um trauma mental, originário dessa consciência, e o surgimento de mitos de uma vida além da morte para aliviar o trauma", entendendo que "a mesma consciência nega e reconhece a morte: nega-a como aniquilamento, reconhece-a como acontecimento" (Morin, 1951/1970, p. 26).

O recalcamento sistemático objetivando a ruptura, a angústia como resultado da presença-ausência, a facticidade e o não saber facilitam a negação da morte por orientarem a crença na imortalidade. Esta se origina na conscientização da finitude e se vê aplacada pela religiosidade e pelas crenças que sustentam os sofrimentos, prometem a continuidade da vida e preenchem o vazio do impensável. Assim, os cerimoniais e as convicções dão sustentação ao sofrimento e ao medo, e as fábulas e o folclore, o tom da representação da morte, consentindo, indiretamente, que se fale dela. "A formidável brecha aberta, dentro de si mesma, pela consciência da morte fez surgir as mais grandiosas 
mitologias que a ocultam, mas sem fazê-la desaparecer" (Morin, 2001/2005b, p.46).

Outra questão presente nos estudos a respeito da morte é o medo que o cadáver desperta. O temor implica as características sobrenaturais que se creem adquiridas depois do passamento. A importância do morto determina atitudes, comportamentos e projeções de sentimentos revelados nos poderes a ele atribuídos, que, a depender da intensidade, incrementam as crenças e lhe conferem visibilidade. $O$ culto às sepulturas de figuras ilustres exemplifica a importância ou a representatividade que as pessoas tiveram em vida, fenômeno denominado por Morin (1951/1970) como a individualidade do morto. O receio da perda da individualidade completa o quadro do traumatismo que a morte provoca por relegar a existência ao nada, aniquilando o sujeito.

A dificuldade em se pensar a morte está diretamente relacionada à penosa reflexão da falta, às ideias de ruptura e desenraizamento, e ao tratamento de um objeto que não pertence ao campo das experiências. As formulações são depreendidas a partir do outro e não do objeto em si (Kastembaum \& Aisenberg, 1976/1986), são desenhadas no processo de socialização, apreendidas como verdade objetiva e interiorizadas como realidade subjetiva, despertando um mosaico de sensações e emoções.

Análises acerca dos sentimentos humanos diante da morte espalham-se pela literatura, especializada ou não, observando que um dos motivos da desorientação humana decorre da necessidade de se colocar a morte à margem da vida e observá-la, preferencialmente a distância, como espectador curioso. Como destaca Carvalho (2009), ninguém espera morrer: "Aceitamos a morte no outro, no anônimo, não em nós e nos nossos queridos" (p. 12).

Nesse sentido, Freud (1915/2006), ao analisar as modificações dos sentimentos diante da morte, avaliou que o "homem primevo assumia uma atitude notável em relação à morte. Longe de ser coerente, era, na realidade, altamente contraditória" (p. 302), pois não demonstrava objeções e nem emoções na morte de adversários ou inimigos, mas, ao enfrentar a perda de entes queridos, viu-se obrigado a defrontar-se com a concretude e os efeitos do acontecimento. Para o autor, a recorrente lembrança dos mortos serviu de base para a suposição de outras formas de existência - como a transmigração das almas e a reencarnação - que originaram a concepção de vida após a morte.

A postulação freudiana apresenta e discute as dificuldades de separação entre vivos e mortos nas conceituações de melancolia - quando toda libido é investida no objeto perdido e permanece nele fixado - e afeto normal do luto - condições internas permitem o direcionamento a outros objetos de amor (Freud, 1917/2006).

De acordo com Cassorla (1992), também em uma abordagem psicanalítica, a consciência da morte configura-se como outra ferida narcísica e de caráter terrorífico, que é fantasiada e serve de ancoradouro ao medo que provoca. Essa proposição indica ausência de controle e poder, e encaminha a adesão às crenças e rituais que explicam e garantem o prolongamento do viver.
O afastamento da morte imposto pela não aceitação da finitude é apresentado no tradicional estudo de Ariès (1975/1977), que marca esse distanciamento por períodos, nomeando-os em referência às atitudes dos homens em cada época. No primeiro período, entre os séculos IX e X, a ideia de morte era constante e revestida pela variedade de exposições, sendo denominado de morte domada. O segundo, nomeado a morte de si mesmo e caracterizado em meados do século $\mathrm{XI}$, desloca a familiaridade com a morte para a preocupação com as particularidades de cada indivíduo e com os pretensos acontecimentos posteriores. $A$ morte do outro é a denominação do próximo período, porque o homem passou a se preocupar menos com a sua própria morte por senti-la arrebatadora e a dedicar atenção à morte do outro. No século $X X$, a morte é considerada vergonhosa e concebida como derrota que precisa ser ocultada e apartada do cotidiano; é identificada como morte invertida, na qual o luto é suprimido e os sentimentos e expressões de dor acobertados (Dias, 1991; Kovács, 1992).

O homem, diante da impossibilidade de negação da morte, procura dominá-la como modo de controle da vida (Kluber-Ross, 1969/2000), mas, ao afastá-la, empobrece seus aspectos simbólicos pela ausência de espaços de reflexão, sobre os quais são construídas imagens e ideias que criam configurações representativas e estabelecem relações de cunho afetivo e cognitivo (Kastembaum \& Aisenberg, 1976/1986). O mal-estar gerado pelo morrer desencadeia sentidos que encaminham espaços obscuros e não resolvidos do existir humano (Leis, 2003), obliterando a possibilidade de reflexão.

Nessa perspectiva, Kovács (2005) aponta o despreparo das escolas em tratar o "fim de nossa existência" ( $p$. 486) com crianças e adolescentes. Sugere que o assunto seja abordado, principalmente, porque mudanças repentinas podem ocorrer na vida e porque a convivência com imagens de morte é constante, sendo imperioso o abandono da cultura do silenciamento. Ressalta a autora a importância do treinamento de professores em serviço, quando seriam privilegiados tópicos que auxiliassem a elaboração de atividades pedagógicas pertinentes, a execução de trabalhos e atividades abordando situações de perda, e oferecidos suportes fílmico e bibliográfico como subsídio a prática. A proposta não pretende a resolução do abalo emocional provocado pela morte, mas um auxílio ao educador em sua função e na continência do aluno enlutado.

Na mesma direção, Rodriguez $(2005,2008)$ ressalva que o acolhimento da escola e dos educadores pode devolver o controle e a segurança aos educandos. Todavia, é preciso considerar que algumas questões atravessam e/ou impedem tal acolhimento, como resistências e dificuldades pessoais ou despreparo teórico- instrumental (Rodriguez, 2010).

Kovács (2005) especifica, ainda, o tratamento dado ao trabalho desenvolvido com adolescentes, alertando para as questões que envolvem esse período do desenvolvimento. Em vídeo produzido para esse fim, destaca comportamentos autodestrutivos e traz "cenas de esportes radicais, 
violência, amor, sexo, uso de drogas, acidentes e tentativas de suicídio, buscando trazer uma visão realista da situação, mostrando como a vida do adolescente pode estar por um fio" (p. 520).

O grande número de mortes entre adolescentes visibilizadas no cotidiano atesta a frágil separação entre o viver e o morrer, e justifica a introdução de eventos escolares/ educacionais que permitam trocas de experiências e exames reflexivos da temática. As indicações dos Parâmetros Curriculares Nacionais (PCN), em seu capítulo referente aos Temas Transversais, auxiliam essa indicação ao observarem a necessidade de "uma tomada de posição diante de problemas fundamentais e urgentes da vida social, o que requer uma reflexão sobre o ensino e a aprendizagem de seus conteúdos: valores, procedimentos e concepções a eles relacionados" (Brasil, 1998, p. 35).

O adolescente é entendido, neste trabalho, como um ser que caminha no sentido da emancipação, é singular, desempenha papéis diversificados, procura desvelar as nuances socioculturais, reflete sobre as condições para o convívio, transforma-se e constitui-se na alterização ${ }^{1}$ envolvido pelas condições de vida e pelos lutos fundamentais (Aberastury \& Knobel, 1970/1980).

O luto pelo corpo infantil escancara as alterações pubertárias e submetem o sujeito às transformações físicas, conferindo-lhe outro lugar que não mais o infantil. O luto pelo papel e identidade infantis refere-se às perdas dos privilégios e à renúncia à dependência familiar, que os lança no futuro misterioso e incógnito repleto de responsabilidades e situações desconhecidas. E o luto pelos pais da infância, que são persistentemente retidos na memória, na tentativa de reencontrar a proteção e os suportes necessários para um caminhar, de idas e voltas, dirigido ao ancoradouro familiar.

O desenvolvimento impele o jovem para frente e essa rota dificulta o vislumbrar do fim, seja por seu potencial desafiador como por seu desejo de avançar, acentuando a angústia básica de morte (Calligaris, 2000), que significa impotência em tempo de concretização e interdição em lugar de prescrição do devir. A "característica da adolescência é viver como se a morte não existisse ou não fosse ocorrer com jovens porque são fortes, poderosos, inteligentes" (Esslinger \& Kovács, 1998/2004, p. 32).

A morte neste século pode ser interpretada como um fenômeno escancarado, "que invade, ocupa espaço, penetra na vida das pessoas a qualquer hora. Pela sua característica de penetração dificulta a proteção e controle de suas consequências: as pessoas ficam expostas e sem defesas" (Kovács, 2003, p. 141). Nesses momentos, escola e família têm grande importância quanto ao manejo dessa situação (Domingos e Maluf, 2003; Kovács, 2005) e, dada sua com-

1 Cf Ciampa (1993): "com esse termo, alterização, se quis expressar a ideia de uma mudança significativa - um salto qualitativo - que resulta de um acúmulo de mudanças quantitativas, às vezes insignificantes, invisíveis, mas graduais e não radicais. Assim, o que se está considerando é a conversão de mudanças quantitativas em mudanças qualitativas" (p.184). plexidade, necessita ser compreendida de uma perspectiva multidisciplinar (Queiroz \& Combinato, 2006).

\section{Método}

Esta investigação foi realizada no município de São Paulo, em uma instituição privada de ensino que apresentava, em seu Projeto Pedagógico, ações educativas crítico-reflexivas, de cunho interdisciplinar de abordagem do fenômeno. Estruturavam-se em dois momentos: (a) leitura e análise do livro "A morte tem sete herdeiros - a noite em que Agatha Christie visitou Jacuruçunga", de autoria de Ganymedes José e Stella Carr (1990); (b) realização de uma redação intitulada "O que é a morte".

As ações foram incorporadas à metodologia. A leitura do livro como mobilizador da temática e o segundo porque os relatos escritos permitem a expressão das concepções pessoais de crenças, sentimentos, valores e opiniões, coincidindo com os objetivos deste estudo (Luna, 2002).

A implantação do projeto de investigação foi precedida da apresentação das metas, dos procedimentos e dos possíveis benefícios aos membros da direção, coordenação, docentes, pais e alunos. Deliberada a presença da pesquisadora na escola, ficou também acordado que os resultados do estudo estariam à disposição dos envolvidos.

O professor de Língua Portuguesa foi designado como coordenador das atividades, especialmente, pela regência da disciplina, o bom relacionamento com os alunos e por organizar outras ações do programa institucional. A adesão a esta proposta se deu pelos mesmos motivos e por seu interesse em discutir a questão. Cabe informar que o referido docente participou de todas as etapas do estudo.

As redações foram realizadas em anos alternados com a finalidade de captação de possíveis mudanças ou alterações nas representações. Nesta perspectiva, programou-se a execução de três redações por participante, sendo a primeira na $6^{\mathrm{a}}$ série do Ensino Fundamental, a segunda na $8^{a}$ série e a terceira no $2^{\circ}$ ano do Ensino Médio, com a mesma questão norteadora.

\section{Participantes}

O primeiro contato ocorreu antes da leitura e discussão do livro, momento em que se efetivou formalmente o convite de participação. Inscreveram-se 21 alunos de duas salas de $6^{a}$ série, com idade variando entre 12-13 anos no início do estudo e 16-17 anos na conclusão, de ambos os sexos, residentes na região metropolitana da cidade e provenientes de famílias de renda média alta.

\section{Resultados}

Enfatiza-se que esta pesquisa limitou-se a fazer um recorte das possibilidades de representação da morte na 
adolescência e apresentar as compreensões e percepções de um grupo de alunos do ensino básico privado.

No decorrer de cinco anos, foram obtidas 113 redações e analisadas 21 , referentes às produções de sete alunos, cinco do sexo masculino e dois do feminino, que participaram das três edições da pesquisa. O número reduzido de produções textuais é explicado por transferências de escola, retenções e/ou ausências dos alunos.

O tratamento das redações seguiu as indicações de Bardin (2004) para análise de conteúdo. Realizou-se, em primeiro lugar, uma leitura flutuante aberta a "todas as ideias, reflexões, hipóteses" (p. 71) e, em segundo, a identificação e contagem de itens de significação que possibilitaram conhecer os sentidos subjacentes aos explícitos. A leitura atenta e repetida das produções, acompanhada de um diálogo constante entre os dados obtidos e a abordagem conceitual, admitiram a apreensão da relação dinâmica e interdependente entre mundo real e sujeito, sujeito e objeto, objetividade e subjetividade (Chizzotti, 1991).

A frequência de determinados temas na construção textual indica a força da transmissão sociocultural das ideias e fantasias acerca da morte, e revela sentimentos e emoções similares aos descritos em adultos e em crianças, a saber:

1 - inevitabilidade da morte: quatro redações na $6^{a}$ série e quatro na $8^{a}$ série do Ensino Fundamental, e quatro no $2^{\circ}$ ano do Ensino Médio;

2 - crenças religiosas: três na $6^{a}$ série, duas na $8^{\mathrm{a}} \mathrm{e}$ quatro no $2^{\circ}$ ano;

3 - vida pós-morte: duas na $6^{a}$ série, quatro na $8^{a} \mathrm{e}$ uma no $2^{\circ}$ ano;

4 - vínculos e dúvidas: nenhuma na $6^{\mathrm{a}}$ série, duas na $8^{\mathrm{a}}$ e quatro no $2^{\circ}$ ano.

A leitura do livro na $6^{a}$ série influenciou, diretamente, a elaboração de três redações narradas com criatividade, semelhantes ao texto original e com a presença de situações tragicômicas, denotando certo distanciamento da questão norteadora, em uma abordagem da morte por vias marginais e situações periféricas: Tudo começou quando meu caranguejo de estimação morreu (L.); Derrepente procurando emprego achei um de engavetador do IML (M.); Um dia, João, Branco, Ricardo e Renato foram ao cemitério, por que eles eram góticos (F.). Outra relata uma situação de luto real vivida e descreve o sofrimento causado pela situação: Eu não vou contar uma história mas vou contar uma história real a 1 mês atrás (P.). As demais expressam a relação entre vida e morte como fato inevitável e indiscutível, associadas à possibilidade de uma vida posterior melhor - O que é a morte? No dicionário existem vários significado fim da vida" (M.) ou A morte está presente na vida de todas as pessoas (R.) -, adicionando a possibilidade de uma vida posterior melhor A morte é uma coisa que acontece com todo mundo. Dizem que quando a pessoa morre vai para um mundo melhor (S). As experiências de enlutamento marcam as relações vinculares, associam-se ao temor da perda e justificam crenças religiosas centralizadas no conforto da continuidade da vida e no reencontro de entes queridos. Não houve expressão de dúvidas.
As produções na $8^{a}$ série evidenciam uma evolução no desenvolvimento do assunto, notada tanto na construção textual como na abordagem do fenômeno. Este passa a ser tratado com atenção diferenciada, especialmente quando defrontado com a realidade, em associação às manifestações emocionais desencadeadas. Nesse momento, abrem-se espaços reflexivos que interrogam as dificuldades de vivenciar o luto, indicando certo amadurecimento dos adolescentes- $A$ morte é um assunto que não pode ser falado na brincadeira (M.) - e incremento da racionalização - [...] só falar que nunca mais quero que aconteça isso não adianta, pois quando tem que acontecer acontece (L.F.). As crenças religiosas descritas apresentam argumentações que procuram, por um lado, confirmar uma vida posterior ou a reencarnação, mostrando certo avanço quando comparadas às realizadas na série anterior, pois tendem a eliminar as incertezas, firmando-se e convicções aprendidas: Essa teoria foi confirmada. Existe vida após da morte (P.), ou Acredito em céu, onde os bons vão para lá; um purgatório, onde as pessoas são julgadas e encaminhadas, ou para o céu ou para o inferno (S.), ou ainda, [...] o que as pessoas acham ou pensam da morte varia de acordo com a religião da pessoas [...] (R.). E, por outro, as dúvidas surgem como ponderação da própria aprendizagem e das transmissões culturais e religiosas: Outras pessoas acham que se a pessoa morre com muita mágoa e muito ódio, essas pessoas vão para um lugar escuro, sombrio [...] (R).

No $2^{\circ}$ ano do Ensino Médio houve um nítido desenvolvimento redacional, em que a sintaxe e a língua culta são observadas com mais cuidado. O raciocínio argumentativo, as considerações e os questionamentos são mais evidentes e as dúvidas têm um caráter desafiador: "Apesar de tudo tenho as minhas dúvidas sobre a morte, pois, se há vida após a morte, nós não morremos, nós, na verdade, vamos para outro mundo. [...]. Mas há outra coisa; se nós reencarnamos nós formamos um ciclo, ou seja, estamos neste mundo, morremos, vamos para outro mundo e depois voltamos para este?" (MM). O mítico e o místico permanecem como referência sociocultural. O temor ao castigo parece relacionado às atitudes em vida, embora se distinguam em qualidade e complexificação das descritas no início da adolescência.

A participação docente esteve limitada à exploração e aos ensinamentos dos componentes próprios da disciplina, marcando um desvio da ideia original do projeto educacional de oferecimento de um espaço reflexivo sobre a morte.

\section{Discussão}

A linguagem humana é o caminho da perpetuação das culturas e manifesta-se na simplificação e na complexidade. Produz objetividade e abstração, marca as pessoas pelas leis, princípios, normas, e/ou pelo misticismo e religiosidade, facilitando, impedindo ou controlando o desenvolvimento social e particular (Morin, 1908/2005a). Permite ainda, a tradução da emocionalidade das experiências que povoam os pensamentos e o ser, e que retroagem sobre 
a própria linguagem. As produções dos alunos denunciam a dependência do contexto em que vivem ao tratarem o ignorado como algo acessível e manipulável, e certa autonomia ao buscarem se desvencilhar do lugar comum que a temática contempla.

Destarte, as redações cumpriram o propósito de apresentar a representação de morte em um grupo de adolescentes, traduzidas em imagens subjetivamente apropriadas. Proporcionaram, também, a manifestação de significados e sentidos na problematização, no diálogo com o conhecimento adquirido, formal ou informalmente, e na confrontação dialógica entre realidade e fantasia.

A difícil tarefa de conceituar a morte reside na impossibilidade de apreensão do objeto, que se realiza apenas via transmissão experencial e determina afirmações decorrentes de trocas de informações - Não sabemos dizer o que é a "morte" (S., 8 a série); Acredito em céu, onde os bons vão para lá (S., $8^{a}$ série); $A$ morte ainda hoje é um grande mistério que a humanidade tenta desvendar (F., $2^{\circ}$ ano); $A$ morte não é castigo de Deus (P., $2^{\circ}$ ano); $A$ morte não é castigo de Deus (L., $6^{a}$ série); Na verdade, acho que ninguém sabe da morte (S., $2^{\circ}$ ano); do empobrecimento dos aspectos simbólicos captados no meio sociocultural e fixados como verdades absolutas que interceptam as dúvidas e as incertezas, e como reflexo da ausência de espaços problematizadores, indicando a necessidade de abertura (Kastembaum \& Aisenberg, 1976/1986).

Os princípios do pensamento complexo são verificados na articulação constante entre produto e causa e entre o todo e as partes. O acompanhamento longitudinal das redações, por série e por alunos, indica uma circularidade temática que faz da morte produto e produtora da vida reveladas em assertivas calcadas na esperança da eternização e na manutenção dos vínculos familiares - [...] é estranho a gente viver eternamente aqui, na terra. É estranho também a gente morrer e não acontecer mais nada. Acredito, um pouco, que depois da morte a gente volta para a Terra, ou seja, um ciclo (S., $8^{a}$ série); A morte para muitas pessoas é o fim. Mau sabem elas que existe vida após a morte" ( $\mathrm{P}$., $8^{\mathrm{a}}$ série); Gostaria de viver aqui eternamente com meus pais, minha irmã e toda minha família” (S., $8^{a}$ série).

Colocar a morte como parte da vida mostra também uma conscientização que busca o controle (Cassorla, 1992; Kluber-Ross, 1969/2000) com a pretensão de descaracterizar a submissão ao desconhecido: - Todos um dia morrerão. (M. A., $8^{a}$ série); Não é preciso ter medo da morte pois todas as pessoas um dia morrerão ( $\mathrm{M}, 2^{\circ}$ ano); Esta é a única certeza de nossas vidas (M. P., $2^{\circ}$ ano); $A$ morte é inevitável (R., $8^{a}$ série); A morte está presente na vida de todos (R., $6^{\mathrm{a}}$ série); A morte é o único fato que, um dia, irá acontecer com todos (M., $2^{\circ}$ ano). A consideração de fenômeno inevitável, ao ser simplificado e colocado objetivamente no exterior, dilui seus efeitos impactantes, concede o afastamento do provável constrangimento desencadeado pelo tema, sinaliza os entraves ao tratar dos sentimentos relacionados à perda, indica a não aceitação do fim (Ariès, 1975/1977; Freud, 1915/2006; Morin, 2001/2005b), ou simplesmente confirma a constatação de uma realidade que atinge narcisicamente o homem (Cassorla, 1992).

Os mitos, as crenças e as religiões fazem parte da memória e do acervo coletivo que se difundem nas individualidades e são projetados no exterior como síntese cognitiva e, nesse sentido, mostram-se como representação: "ato constitutivo idêntico e radical do real e do imaginário" (Morin, 2001/2005b, p. 123, grifos do autor). Os adolescentes descrevem suas convicções, mesmo que temporárias - Eu também não acredito na vida após a morte, como acreditam pessoas de outras religiões, eu acredito que depois da morte não existe mais nada (M. A., $8^{a}$ série); Apesar de tudo eu tenho minhas dúvidas sobre a morte, pois se há vida após a morte, nós não morremos, nós na verdade vamos para outro mundo (M. P., $2^{\circ}$ ano) - e mostram que, no processo de amadurecimento, novos conhecimentos são adquiridos, facilitando o empreendimento de um diálogo que encaminha à compreensão, à aceitação e/ou à inconformação.

A conscientização da inevitabilidade da morte física pode gerar tanto resistências e defesas contra o terror despertado como posicionamentos definidos e irredutíveis, como resultado de avaliação desprovida de fantasia e fincada na realidade - O que é a morte? No dicionário existem vários significados como: fim da vida, ato ou efeito de morrer [...] na minha opinião a morte é apenas o fim da vida (M., 6a série); A morte vem quando menos se espera (M. P., $8^{a}$ série); Não é preciso ter medo da morte, pois todas as pessoas irão morrer um dia, e quando chegar a hora, não tem jeito, a pessoa morre mesmo (M., $6^{\mathrm{a}}$ série.).

As redações revelam a estranheza dos adolescentes em conciliar vida e finitude, não como dúvida, mas como incerteza do devir. Como propõe o pensamento moriniano, tal inconciliação remete à circularidade dos afetos e emoções, na qual as causas se revelam nos efeitos e nos produtos necessários à sua produção e na união de verdades contraditórias. As afirmações e questionamentos sobre a reencarnação como modo de purificação expressam esse movimento - Nosso corpo, matéria, é que fica na terra em decomposição. Nossa alma, espírito, é que volta ao começo para reiniciar um novo ciclo de vida (P., $2^{\circ}$ ano).

A imaginável chance de viver novamente parece aplacar a incerteza e a angústia que o tema desperta, pois a morte se confronta com o desenvolvimento e com a perspectiva de futuro. É um estancamento do fluxo da vida que assusta por não apresentar condições de reposição. A reencarnação, por sua vez, leva à ideia de lugares mais agradáveis de (con)vivência, sugerindo proteção contra sentimentos incômodos e dolorosos, e apropriadas dos descolamentos das religiões que pregam a vida pós-morte, que, de certo modo, reduzem a dificuldade de aceitação do fim. Nesse aspecto, poder-se-ia pensar também na influência da tradição religiosa que dá contornos à constituição subjetiva.

O tratamento das redações mostra atos constitutivos idênticos e radicais do real e do imaginário, evidenciando antagonismos e complementaridades ao destacarem o conhecido e o desconhecido que se entretecem e se separam, mostrando que a morte invertida apresenta outros matizes 
neste grupo de adolescentes e que a supressão da dor e dos sentimentos está presente no cotidiano, na fantasia e/ou nas redes sociais, como morte escancarada.

Assim, observam-se, na realidade e no imaginário, elementos comuns e elementos distintos que se interligam e se completam mutuamente, que, como mostra Morin (2001/2005b), são angariados na experiência pessoal e na histórico-coletiva, estão presentes na tradição e são construídos pela via da educação. Poucos jovens tiveram perdas de morte de entes próximos, mas aqueles que as experimentaram parecem tratá-la como vivência, assistida e sentida pela consciência, até porque, pela própria juventude, não houve tempo de se instalarem como experiência. Contudo, a intensidade contida em cada descrição sinaliza que, de alguma maneira, todos prospectam as emoções provocadas por um luto concreto.

Como assinala Freud (1915/2006), foram os sentimentos de culpa e ódio que impediram o homem do afastamento da morte, sentindo-a em si mesmo. O conteúdo de alguns relatos autoriza a inferência da existência desses sentimentos: Eu pretendo ter uma vida limpa em que eu consiga chegar em casa e dormir sem nenhum peso na consciência (F., $2^{\circ}$ ano).

Não é possível o estabelecimento de nexos entre a morte alimentada pela leitura do livro e os lutos infantis anunciados por Aberastury e Knobel (1970/1980). Pode-se afirmar que os adolescentes explicitaram os afetos despertados pelo tema e sugerir que as descrições, em seu conteúdo latente, referem-se ao descolamento provocado pelo desenvolvimento e pela separação parental.

As produções femininas evidenciaram uma distinção de gênero: as adolescentes mostraram maior distanciamento da temática, associada à reflexão de situações de morte permeadas por conteúdos racionais. Os adolescentes mostraram-se mais emocionais, preocupados com o acolhimento e conforto em situações de sofrimento, sem, entretanto, abandonar a racionalidade, podendo-se supor uma desconstrução das imagens pressupostas de fragilidade feminina e frieza masculina frente a situações dolorosas. Ou uma demanda interna que mostra "a vida do adolescente pode estar por um fio” (Kovács, 2005, p. 520).

O professor realizou uma análise voltada, exclusivamente, para o conteúdo formal, gramatical e estético das composições, desconsiderando a proposição inicial de discussão, reflexão e acolhimento, bem como prejudicando e fragmentando as indicações de integração e transversalidade disciplinar presentes nos PCN. Essa atitude admite a suposição da dificuldade do trato do assunto, exposta pelo enclausuramento da morte como forma mágica de apartá-la, e/ou o despreparo na formação dos educadores para questões do cotidiano escolar. O sujeito/educador parece levar de roldão as narrativas efetivadas na transmissão social, juntamente com as suas, absorvendo as vivências como força de conhecimento e relegando a morte a lugares preservados da consciência. Como aborda Kovács (2005), o treinamento docente pode facilitar o contato com a questão da morte, que, por sua vez, facilitará as análises críticas e os suportes emocionais aos alunos enlutados.
O processo adolescente, aparentemente, não influenciou a apreensão sociocultural da morte, já que as manifestações descrevem os mesmos conteúdos descritos por pesquisadores que se dedicaram a discorrer sobre o tema. Embora considerado, por parte dos especialistas, período conflituoso e tensivo, não se identificou acentuação em função da adolescência, nem naqueles que viveram perdas significativas.

As redações cumpriram o propósito de apresentar a representação de morte em um grupo determinado de adolescentes. Proporcionaram, também, um tempo de manifestação de significados e sentidos, e de problematizações e diálogos com o conhecimento adquirido e com aspectos da realidade, da fantasia, da mitologia, da religiosidade e das crenças.

\section{Finalizando}

A análise das produções aponta para a contradição existente entre vida e morte, confirmando outros estudos. Os alunos reafirmam o conflito entre o que é natural e inevitável em contraste com o período de descobertas, crescimento e prospecção de futuro.

A representação da morte apóia-se na combinação de ideias e sentimentos que se estendem espacial e temporalmente. O texto literário teve pouca influência, persistindo nas redações a força da transmissão cotidiana e permanente de sentidos, atitudes e comportamentos apreendidos no convívio e por intermédio da cultura. As características fundantes estão mantidas sem eliminar o sentido individual e singular, havendo uma ressignificação das experiências coletivas. Observa-se a negação do aniquilamento pela esperança da vida após a morte, presente na chance de purificação e reencarnação.

O tema provocou angústias existenciais nos alunos, principalmente quando abordada a passagem do tempo para si mesmo e para as pessoas próximas, levando-os a empreender uma análise desviada, compensatória e/ou de negação, visto que a morte permanece como sujeito ausente do discurso e dificulta, impede, ou mesmo os defende do contato com o sofrimento antecipado.

A análise das redações sugere que o cotidiano escolar está marcado pela qualidade e intensidade da relação professor-aluno, que pode se configurar como um dos elementos que contribuem para o isolamento ou para a aproximação de questões relativas à existência e ao próprio contexto educacional.

A formação do educador especialista tangencia o estudo dos fenômenos juvenis e encaminha à cristalização da ideia de período turbulento, que embarga a aproximação e a compreensão da adolescência como momento produtivo e criativo. O professor que integrou este projeto de pesquisa deixou dúvidas se o seu distanciamento respondia à adolescência ou à temática. Todavia, não se pode desconsiderar a importância vital de sua participação para a realização, coordenação do trabalho e condução da disciplina. 
Em uma das raras referências à educação, Freud (1910/2006) afirma que uma escola de Ensino Médio deve dar aos seus alunos "o desejo de viver e devia oferecer-lhes apoio e amparo numa época da vida em que as condições de seu desenvolvimento os compelem a afrouxar seus vínculos com a casa dos pais e com a família" (p. 243). Embora a instituição tenha como proposição a continência de seus alunos, ainda não alcançou esse estágio.

A identificação de uma instituição de ensino que se preocupa em discutir questões relativas à morte anuncia um avanço considerável às práticas rotineiras e uma tentativa de evitar a mesmice, ao oferecer apoio aos educandos em momentos de dor e/ou dificuldades, independentemente do período do desenvolvimento. Mas as ações não podem vir isoladas. É fundamental considerar a formação em serviço, apoio ao professor, consistência às reflexões do alunado e a influência da subjetividade.

Os estudos e pesquisas efetuados por Freud (1917/2006), Ariès (1975/1977), Cassorla (1992), Aberastury e Knobel (1970/1980), Morin, (1951/1970, 1980/2005a), Kovács $(1998,2005)$, entre outros, mostram que o homem contemporâneo - e o mesmo pode-se dizer dos adolescentes que participaram desta investigação - não enfrenta a morte com facilidade, mas busca formas de compreendê-la e apreender o inevitável. Diante desse quadro, entende-se que a escola tem a função de abrir-se à discussão sobre a morte e a finitude, alargando os domínios restritos à sistematização do conhecimento.

\section{Referências}

Aberastury, A., Knobel, M. (1980). Adolescência normal (S. M. G. Ballve, Trad.). Porto Alegre: Artes Médicas. (Texto original publicado em 1970)

Ariès, P. (1977). História da morte no Ocidente (P.V. de Siqueira, Trad.). Rio de Janeiro: Francisco Alves. (Texto originalmente publicado em 1975)

Bardin, L. (2004). Análise de conteúdo (L. A. Reto \& A. Pinheiro, Trad.). Lisboa: Edições 70.

Berger, P. L., \& Luckmann, T. (1974). Construção social da realidade: tratado de sociologia do conhecimento (F. S. Fernandes, Trad.). Petrópolis, RJ: Vozes. (Texto original publicado em 1966)

Calligaris, C. (2000). A adolescência. São Paulo: Publifolha.

Carvalho, F. P. B. de. (2009). A morte na concepção de estudantes de enfermagem. Dissertação de mestrado, Faculdade de Enfermagem da Universidade Federal do Rio Grande do Norte, Natal, Rio Grande do Norte.
Cassorla, R. (1992). Reflexões sobre a Psicanálise e a Morte. Em M. J. Kovács, Morte e desenvolvimento humano (pp. 90-110). São Paulo: Casa do Psicólogo.

Chizzotti, A. (1991). Pesquisa em ciências humana e sociais. São Paulo: Cortez.

Ciampa, A. da C. (1993). A estória de Severino e a história de Severina, um ensaio de Psicologia Social. São Paulo: Brasiliense.

Dias, M. L. (1991). Suicídio: testemunhas do adeus. São Paulo: Brasiliense.

Domingos, B., \& Maluf. M. R. (2003). Experiências de perda e de luto em escolares de 13 a 18 anos. Psicologia: Reflexão e Crítica, 16(3), 577- 589

Esslinger, I., \& Kovács, M. J. (2004). Adolescência: vida ou morte? (2a ed.). São Paulo: Ática. (Texto original publicado em 1998)

Freud, S. (2006). Luto e melancolia (Vol. XIV). Edição Standard Brasileira das Obras Psicológicas Completas. (J. Salomão, Trad.). Rio de Janeiro: Imago. (Texto original publicado em 1910)

Freud, S. (2006). Reflexões para os tempos de guerra (Vol. XIV). Edição Standard Brasileira das Obras Psicológicas Completas. (J. Salomão, Trad.). Rio de Janeiro: Imago. (Texto original publicado em 1915)

Freud, S. (2006). Contribuições para uma discussão acerca do suicidio (Vol. XI). Edição Standard Brasileira das Obras Psicológicas Completas. (J. Salomão, Trad.). Rio de Janeiro: Imago. (Texto original publicado em 1917)

Ganymédes J., \& Carr, S. (1990). A morte tem sete herdeiros - a noite em que Agatha Christie visitou Jacuruçunga. São Paulo: Moderna.

Kastenbaum, R., \& Aisenberg, R. (1986). Psicologia da morte. (A. P. Lessa, Trad.). São Paulo: Pioneira. (Texto original publicado em 1976)

Kovács, M. J. (1992). Morte e desenvolvimento humano. São Paulo: Casa do Psicólogo.

Kovács, M. J. (2003). Educação para a morte: temas e reflexões. São Paulo: Casa do Psicólogo.

Kovács, M. J. (2005). Educação para a morte. Psicol. cienc. prof., 25(3), pp.484-497. [online]. Recuperado: 21 mai 2010. Disponível: $\quad<$ http://pepsic.bvs-psi.org.br/scielo.php?script=sci_ arttext\&pid=S1414-98932005000300012\&Ing=pt\&nrm=iso $>$. ISSN 1414-9893

Kübler-Ross, E. (2000). Sobre a morte e o morrer (P. Menezes, Trad.). São Paulo: Martins Fontes. (Texto original publicado em 1969). 
Leis, H. R. (2003). A sociedade dos vivos. Sociologias, 9, pp. 340-353.

Luna, S. V. de. (2002). Planejamento de pesquisa: uma introdução. São Paulo: EDUC.

Morin, E. (1970). O homem e a morte. (J. G. Boto \& A. Rodrigues, Trads.). Lisboa: Europa-América. (Texto original publicado em 1951).

Morin, E. (2005a). O método 2: a vida da vida (M. Lobo, Trad.). Porto Alegre: Sulinas. (Texto original publicado em 1980).

Morin, E. (2005b). O método 5: a humanidade da humanidade (J. Machado, Trad.). Porto Alegre: Sulinas. (Texto original publicado em 2001).

Morin, E., Almeida, M. C., \& Carvalho, E. A. (2002). Educação e complexidade: os sete saberes e outros ensaios. São Paulo: Cortez.

Queiroz, M. S., \& Combinato, D. S. (2006). Morte: uma visão psicossocial. Revista Estudos de Psicologia, 11(2), pp. 209-216. Recuperado: 3 ago 2009. Disponível: <http://www.scielo.br/pdf/ epsic/v11n2/a10v11n2.pdf>
Rodriguez, C. F. (2005). O que os jovens têm a dizer sobre a adolescência e o tema morte? Dissertação de mestrado, Instituto de Psicologia, Universidade de São Paulo, São Paulo.

Rodriguez, C. F. (2008). Adolescentes - vidas interrompidas: por que é tão importante falar sobre morte com eles? Em Kovács, M. J. (Org.), Morte e existência humana: Caminhos de cuidados e possibilidade de intervenção (pp. 16-43). Rio de Janeiro: Guanabara Koogan.

Rodriguez, C. F. (2010) Falando de morte na escola: o que os educadores têm a dizer? Tese de Doutorado, Instituto de Psicologia, Universidade de São Paulo, São Paulo.

Secretaria de Educação Fundamental. (1998). Parâmetros curriculares nacionais: terceiro e quarto ciclos: apresentação dos temas transversais. Secretaria de Educação Fundamental. Brasília: MEC/SEF.

Torres, W, Guedes, W. G., \& Torres, R. C. (1983). A psicologia e a morte. Rio de Janeiro: Fundação Getulio Vargas.

\section{Sobre a autora}

Elaine Teresinha Dal Mas Dias (etdmd@terra.com.br)

Universidade Nove de Julho

Endereço para correspondência:

Avenida Caxingui, 231, apto 52. Vila Pirajussara, São Paulo/SP - CEP: 05579000 